\title{
Genome-wide association study for calving traits in Danish and Swedish Holstein cattle
}

\author{
G. Sahana, ${ }^{1}$ B. Guldbrandtsen, and M. S. Lund \\ Aarhus University, Faculty of Agricultural Sciences, Department of Genetics and Biotechnology, Research Centre Foulum, DK-8830, Tjele, \\ Denmark
}

\begin{abstract}
A total of 22 quantitative trait loci (QTL) were detected on 19 chromosomes for direct and maternal calving traits in cattle using a genome-wide association study. Calving performance is affected by the genotypes of both the calf (direct effect) and dam (maternal effect). To identify the QTL contributing these effects to calving characteristics, we performed a genome-wide association study using a mixed-model analysis in Danish and Swedish Holstein cattle. The analysis incorporated 2,062 progeny-tested bulls, and 36,387 single nucleotide polymorphism markers on 29 bovine autosomes were analyzed for association with 14 calving traits. Strong evidence for the presence of QTL that affect calving traits was observed on chromosomes 4, 6, 12, 18, 20, and 25. The QTL intervals were generally smaller than those described in earlier linkage studies. The identification of calving trait-associated single nucleotide polymorphisms and mapping of the corresponding QTL in small chromosomal regions will facilitate the search for candidate calving performance genes and polymorphisms.
\end{abstract}

Key words: Bos taurus, calving trait, genome-wide association, quantitative trait loci

\section{INTRODUCTION}

Reduced calving performance in cows is associated with economic loss, as well as diminished animal welfare due to loss of calves from stillbirth and the extra work and veterinary costs resulting from dystocia. For instance, an increased stillbirth rate reduces the number of potential replacement heifers in a dairy cattle herd, whereas dystocia negatively affects calf survival via multiple mechanisms, including prolonged hypoxia and potential trauma. Recently, important genetic associations have been made between gestation length and birth weight (Crews, 2006). These factors in turn

Received April 27, 2010.

Accepted September 27, 2010.

${ }^{1}$ Corresponding author: goutam.sahana@agrsci.dk have a significant genetic relationship with calving ease (Gutiérrez et al., 2007; Phocas, 2009).

A direct effect on calving performance refers to the additive genetic effect of the genotype of the calf, whereas the maternal effect refers to the additive genetic effect of the genotype of the calf's dam. However, the heritability estimates of calving traits measured as direct effects $\left(h^{2}=0.05\right.$ to 0.19$)$ are higher than the heritability estimates of the calving traits measured as maternal effects $\left(h^{2}=0.04\right.$ to 0.06$)$ in Danish Holstein cattle (Hansen et al., 2004). In addition, genetic correlations for direct calving traits between first and later calvings were estimated to range from 0.97 to 0.99 , whereas for maternal calving traits, the values were between 0.81 and 0.89 (Aamand, 2002). Furthermore, small antagonistic genetic correlations $(-0.07$ to -0.1$)$ have been found between the direct and maternal effects in first lactation by several authors (Manfredi et al., 1991; Harbers et al., 2000; Steinbock et al., 2003; Cole et al., 2007), whereas Ducrocq (2000) obtained a genetic correlation of 0 between direct and maternal effects of calving difficulties in all lactations. The low, and likely antagonistic, correlation between direct and maternal effects emphasizes the importance of including both traits in a genetic evaluation program. Stillbirth rates, calving ease, and calf size at birth are all included in the Danish cattle breeding program (Pedersen et al., 2008). However, the genetic trend from 1990 to 2004 for calving and birth indices in Danish, Swedish, and Finnish Holstein cattle did not show the desired improvements (Boelling et al., 2007). For example, the incidence of stillbirth in Danish Holstein cattle has increased during the last 2 decades (Hansen et al., 2004). These trends suggest that the efficiency of current breeding practices in improving calving characteristics is limited, given their current weight in the breeding goal. This is likely due to their low heritability, as well as low and, in some cases, antagonistic, correlation among direct and maternal calving traits.

Several QTL have been detected for calving traits using linkage-based QTL mapping (Schrooten et al., 2000; Kühn et al., 2003; Holmberg and AnderssonEklund, 2006; Holmberg et al., 2007; Thomasen et 
al., 2008); however, the QTL intervals reported were very large and unsuitable for candidate gene searches. Furthermore, QTL identified by linkage analysis can typically be used only for within-family selection. In contrast, association mapping is based on direct marker effects and utilizes population-wide linkage disequilibrium of markers with causative genes. Results derived from association mapping of calving traits would be of immediate use in breeding programs because allelic variation present in the entire population can be utilized. In practice, genome-wide association study (GWAS) results are used to prioritize chromosomal regions for further study or additional typing. Genomic selection is a new technology in animal breeding, which selects animals for breeding based on breeding values predicted directly from genome-wide dense markers of animals (Hayes et al., 2009). In genomic selection, it is then possible to establish different priority weights for individual SNP based on their established association with the phenotype of interest, which could increase the success rate of genomic prediction.

In the present study, association mapping was carried out for 14 calving traits in dairy cattle using SNP markers in a GWAS. The objective was to detect QTL affecting the direct and the maternal calving traits in Danish and Swedish Holstein cattle populations.

\section{MATERIALS AND METHODS}

\section{Animals and Phenotypes}

Progeny-tested Danish and Swedish Holstein bulls were genotyped, and single-trait-estimated breeding values (STBV) were used as phenotypic records. Phenotypic observations were available for analysis of 2,062 bulls, with the exception of birth and calving indices, whereas STBV were available for 1,948 bulls. The STBV were estimated by best linear unbiased procedures using a single-trait sire model and were adjusted for systematic environmental effects, as done routinely for Nordic cattle genetic evaluation. Two STBV were calculated for each animal: 1 for first parity, and the other for combined second and later (up to fifth) parities. Data were edited according to national editing rules, including removal of twin pregnancies, crossbred pregnancies, and pregnancies resulting from embryo transfer. Separate STBV were calculated for direct and maternal effects. The direct effect represents the additive effect of the genotype of the calf being born. The maternal effect represents the additive genetic effect of the genotype of the cow giving birth. Breeding values were standardized to an average of 100 and a standard deviation of 10 index units, with standardization factors calculated from the sire population born in 1997 to
1998. The data-recording systems and breeding value estimation for calving traits in Denmark and Sweden were described previously (Boelling et al., 2007). Additional details about the traits and method of estimation of breeding values are available on the Nordic Cattle Genetic Evaluation website (http://www.nordicebv. info/Forside.htm).

Three traits were recorded for each calving. In Denmark, calving ease $(\mathbf{C E})$ was reported by the farmer as a subjectively scored categorical trait with 4 levels (1 to 4$): 1=$ easy calving without help; 2 = easy calving with help; 3 = difficult calving without veterinarian assistance; $4=$ difficult calving with veterinarian assistance, including Cesarean sections. In Sweden, CE scores were recorded on a 2-point scale, but were transformed to approximate the Danish scale. Calf size (CS) was recorded by the farmer as a subjectively scored categorical trait with 4 levels. Finally, stillbirth (SB) was recorded as a binary variable indicating whether the calf was alive $24 \mathrm{~h}$ after birth. For each of these 3 recorded traits, 4 STBV were calculated: 1 for each combination of direct (D) and maternal (M) effect, and first $(\mathbf{F})$ and later $(\mathbf{L})$ pregnancy. For example, the STBV for a direct genetic effect for stillbirth in second and later lactations was designated DSBL.

Additionally, 2 combined indices were analyzed. The birth index (BI) is a compound index describing a sire's total direct additive genetic effect on $\mathrm{CE}$ by combining DSBF, DSBL, DCEF, DCEL, DCSF, and DCSL. Likewise, the calving index $(\mathbf{C I})$ is a compound index describing the maternal additive genetic effect on calving ease by combining the equivalent maternal STBV. The subtraits are combined using an economically weighted average (for economic weights, see Pedersen et al., 2008).

\section{SNP Chip and Genotyping}

We used the BovineSNP50 Beadchip (Illumina Inc., San Diego, CA) to genotype 2,531 animals (for details on SNP genotyping, see Sahana et al., 2010). This assay includes 54,001 markers with a median interval of $37 \mathrm{~kb}$ between SNP. The SNP with a minor allelic frequency of $<5 \%$, or with call rates $<95 \%$, were excluded. Likewise, individuals with call rates $<85 \%$, or average GC scores of $<0.65$ were excluded. The minimum accepted GC score for individual typings was 0.60. After editing, the final marker set included 36,387 SNP on 29 bovine autosomes. The number of SNP included for analysis varied between 2,320 on BTA1 and 675 on BTA28. The SNP positions within a chromosome were based on the Baylor College of Medicine Human Genome Sequencing Centre's Bos taurus genome assembly (Btau_4.0; Liu et al., 2009). 


\section{Statistical Methods for Association Analysis}

Mixed Model. The mixed model analysis (MMA) as proposed by $\mathrm{Yu}$ et al. (2006) was used for association analysis. A polygenic genetic effect was fitted as a random effect and genotypes at individual SNP were successively included as a fixed effect in an MMA. The model used was as follows:

$$
\mathbf{y}=\mu+\mathbf{Z u}+\mathbf{S} \boldsymbol{\alpha}+\mathbf{e}
$$

where $\mathbf{y}$ is a vector of phenotypes, $\mu$ is general mean, $\mathbf{Z}$ is a matrix relating additive polygenic effects to individuals, $\mathbf{u}$ is a vector of additive polygenic effects, $\boldsymbol{\alpha}$ is a vector of SNP effects (of marker types $0,1,2$ ), $\mathbf{S}$ is an incidence matrix relating elements of $\boldsymbol{\alpha}$ to the individuals, and $\mathbf{e}$ is a vector of random residual effects. The random variables $\mathrm{u}$ and e are assumed to be normally distributed. Specifically, u is normally distributed with $\left(0, \sigma_{g}^{2} \mathbf{A}\right)$, where $\sigma_{g}^{2}$ is the polygenic genetic variance and $\mathbf{A}$ is the additive relationship matrix derived from the pedigree. The analysis was carried out using the software package DMU (available at http://dmu.agrsci. $\mathrm{dk})$.

Significance Test. The significance of each marker's effect was tested using a $t$-test against a null hypothesis assumption that the allele substitution effect is equal to zero. To control the family-wise error rate, the Bonferroni correction was applied. The $5 \%$ chromosome-wise significance thresholds ranged from the point-wise $P$ value of $2.16 \times 10^{-5}$ on BTA1 to $7.41 \times 10^{-5}$ on BTA28, or 4.67 to 4.13 in the $-\log _{10}$ transformed scale. Because Bonferroni correction is very conservative (Han et al., 2009), we used a suggestive significance threshold of $10^{-4}$. In the following sections, a significant association will mean chromosome-wise significance, and a suggestive association means a point-wise $P$-value of $<0^{-4}$.

Marking the QTL Region. Normally, multiple SNP near a QTL are expected to yield significant results in a single SNP analysis. This is because sets of SNP that are physically near the causal factor will tend to be in linkage disequilibrium; this effect declines with genetic distance and also depends on minor allele frequency. Considering this, the boundaries of a QTL region can be marked by looking for markers flanking an SNP hit where the $-\log _{10}(P$-value $)$ returns to background noise levels (Wellcome Trust Case Control Consortium, 2007). In this study, QTL regions were demarcated subjectively. Starting at the most significant SNP, the QTL region was extended left and right until a region was reached where all markers had a $-\log _{10}(P$-value $)$ below 3 , indicating that the QTL thus demarcated may contain 1 or more nonsignificant markers. To compare results from the present study with past studies, we took the marker position from Btau_4.0 (Liu et al., 2009).

\section{RESULTS}

In our search for QTL affecting calving traits, we identified 22 QTL regions on 19 chromosomes in Danish and Swedish Holstein cattle (Table 1). Nine of the QTL were related to direct calving effects, whereas 5 were related to maternal effects, and 8 affected both direct and maternal calving traits. All SNP and associated traits that crossed the chromosome-wise significance threshold are presented in supplementary Table 1. Genome-wide significant $(P<0.05)$ QTL were observed on 6 chromosomes: BTA4, 6, 12, 18, 20, and 25. In addition, $45 \mathrm{SNP} /$ trait combinations were found to be significant genome-wide on BTA18, whereas on other chromosomes, 9 SNP showed genome-wide significant associations with calving traits. In addition, we found evidence for 2 QTL segregating on 3 chromosomes, including BTA3, 18, and 25. Highly significant QTL associated with direct calving traits were observed on BTA4, 12, 18, and 25. However, for maternal calving traits, the highly significant QTL were observed on BTA6 and 20. Chromosome-wise significant associations with SNP were found for all the maternal calving traits in the first lactation, whereas only a few associations were significant for later lactations. Furthermore, only 1 chromosome-wise significant SNP was found to be associated with MCEL, whereas no significant SNP associations were found for MSBL and MCSL.

The signal plots for BI and CI (Figure 1) and other calving traits analyzed (Supplementary data available online: http://www.journalofdairyscience.org/) give an overview of how the SNP associations were distributed across the genome and aid in the visualization of QTL or genomic regions affecting more than one trait. The strongest association signal was observed on BTA18, where strong associations were observed for several direct calving traits. Similarly, on BTA25, the association signals crossed the threshold for suggestive significance for DCSF, DCSL, MCSF, DSBF, DCEL, BI, and CI. In addition, regions on BTA3, 12, and 20 also were found to affect more than one calving trait.

\section{DISCUSSION}

In the present study, we identified several QTL that are significantly associated with direct and maternal calving traits, confirming many of the earlier QTL detected in Danish Holstein (Thomasen et al., 2008) and other cattle populations (e.g., Kühn et al., 2003; Ashwell et al., 2005; Schnabel et al., 2005). In general, the QTL intervals we observed were narrower com- 
Table 1. The SNP with the lowest $P$-value (highest significance) within a QTL region and the boundary of the QTL detected using association mapping for calving traits ${ }^{1}$

\begin{tabular}{|c|c|c|c|c|c|c|c|c|c|}
\hline \multirow[b]{2}{*}{$\begin{array}{l}\text { Chromosome } \\
\text { no. }\end{array}$} & \multirow[b]{2}{*}{$\begin{array}{l}\text { QTL region/ } \\
\text { chromosome }\end{array}$} & \multicolumn{2}{|c|}{ Lower bound } & \multicolumn{2}{|c|}{ Upper bound } & \multicolumn{3}{|c|}{ Top SNP } & \multirow{2}{*}{$\begin{array}{l}\text { Traits with } \\
\text { significant/ } \\
\text { suggestive } \\
\text { association }\end{array}$} \\
\hline & & SNP & $\begin{array}{l}\text { Pos }^{2} \\
(\mathrm{bp})\end{array}$ & SNP & $\begin{array}{l}\text { Pos } \\
\text { (bp) }\end{array}$ & SNP & $\begin{array}{l}\text { Pos } \\
\text { (bp) }\end{array}$ & $-\log _{10}(P)$ & \\
\hline 1 & 1 & ss86293375 & $138,836,143$ & rs 43282740 & $141,061,623$ & ss61562427 & $140,191,583$ & 5.26 & BI, DCEL, DCSL \\
\hline 3 & 1 & ss86274798 & $11,316,000$ & ss 86304033 & $15,727,740$ & ss86304033 & $15,727,740$ & 5.55 & DCSF, BI, DCSL, DCEF \\
\hline 3 & 2 & ss 86329444 & 90.496 .720 & ss 86292962 & $108,800,552$ & ss 86329444 & 90.496 .720 & 5.77 & MCSF, CI, MCEF, MSBF \\
\hline 4 & 1 & ss61554103 & $43,485,808$ & ss 86306000 & $48,781,574$ & $\mathrm{rs} 29011243$ & $46,920,709$ & 6.72 & DSBL, MCEL \\
\hline 6 & 1 & ss86308042 & $115,101,936$ & ss 86301337 & $119,038,392$ & ss86341026 & $118,175,859$ & 7.36 & MCEF, CI \\
\hline 7 & 1 & $\begin{array}{l}\text { rs } 41625107 \\
\end{array}$ & $90,585,180$ & rs41595681 & $100,579,805$ & ss61527653 & 91.119 .703 & 4.89 & BI. DCSF, DCSL \\
\hline 9 & 1 & ss61493479 & $91,239,057$ & ss 86325640 & $100,643,615$ & ss 86294729 & $98,048,063$ & 4.73 & CI, MCEF, MSBF \\
\hline 10 & 1 & ss117970005 & $32,331,352$ & rs29013224 & $33,312,367$ & rs29013224 & $33,312,367$ & 5.08 & MCEF \\
\hline 12 & 1 & Ss86289721 & 23.541 .171 & ss 86307235 & $32,847,909$ & rs29013272 & 26.952 .729 & 6.41 & DCSL, BI. DCSF, DCEL \\
\hline 13 & 1 & ss 86290731 & $57,750,019$ & ss 86296563 & $57,904,589$ & Ss 86296563 & $57,904,589$ & 5.48 & DCSL, BI \\
\hline 15 & 1 & ss 86306632 & $66,656,861$ & Ss86296181 & $67,698,361$ & ss86310149 & $67,554,655$ & 4.48 & MCEF, DCEF, CI \\
\hline 18 & 1 & ss61482552 & $14,058,411$ & ss117972313 & $14,088,147$ & ss117972313 & $14,088,147$ & 5.69 & DCSF, BI, DCEL \\
\hline 18 & 2 & ss 86324299 & $55,177,426$ & ss 86289990 & $60,027,078$ & ss86324977 & $57,125,868$ & 29.12 & $\begin{array}{l}\text { DSBF, DSBL, BI, } \\
\text { DCEF, DCEL, DCSF, DCSL }\end{array}$ \\
\hline 19 & 1 & ss 86291810 & $25,326,224$ & ss 86294536 & $41,982.803$ & Ss86296300 & $34.471,562$ & 5.00 & MCEF, CI. DCSF, DCSL, DCEF \\
\hline 20 & 1 & ss 86312995 & $19,455,192$ & rs29018884 & $28,825,168$ & ss61509110 & $28,665,905$ & 7.16 & CI, MCSF, DCSL, MCEF \\
\hline 21 & 1 & ss 86308832 & $43,758.618$ & ss 86281424 & 47.536 .347 & ss86281424 & 47.536 .347 & 4.91 & DCSF, DCSL \\
\hline 23 & 1 & rs29016513 & $11,015,543$ & ss 86287227 & $11,812,412$ & ss86287227 & $11,812,412$ & 4.80 & CI, DCEF \\
\hline 25 & 1 & ss61548284 & $17,067,523$ & ss86340784 & $23,953,842$ & ss61548284 & $17,067,523$ & 4.82 & CI, DCSL, MCSF \\
\hline 25 & 2 & ss61570688 & $30,490,116$ & ss 86306187 & $38,046,492$ & rs29012599 & $30,581,871$ & 6.22 & $\begin{array}{l}\text { DCSL, DCEL, CI, DCSF, } \\
\text { MCSF, DCEL, BI, DSBF }\end{array}$ \\
\hline 26 & 1 & ss117963058 & $39,720,948$ & ss 86282826 & $41,950,047$ & ss 86282826 & $41,950,047$ & 5.13 & DCEL, MCSF \\
\hline 28 & 1 & ss86329711 & $7.155,869$ & ss 86337391 & 7.322 .504 & ss86337391 & $7.322,504$ & 4.51 & MSBF. CI \\
\hline 29 & 1 & rs43707613 & 9.543 .767 & ss 86336322 & 10.929 .512 & ss61488729 & 10.557 .765 & 4.94 & DCSF, DCSL, BI \\
\hline
\end{tabular}

${ }^{1}$ The QTL that were significant genome wide are in bold.

${ }^{2} \mathrm{Pos}=$ position.

${ }^{3}$ Prefixes: $\mathrm{D}=$ direct effect; $\mathrm{M}=$ maternal effect. Calving traits: $\mathrm{BI}=$ birth index; $\mathrm{SB}=$ stillbirth; $\mathrm{CE}=$ calving ease; $\mathrm{CS}=$ calf survival; $\mathrm{CI}=$ calving index. Suffixes: $\mathrm{F}=$ first lactation; $\mathrm{L}=$ later lactation. 
Birth Index (BI)

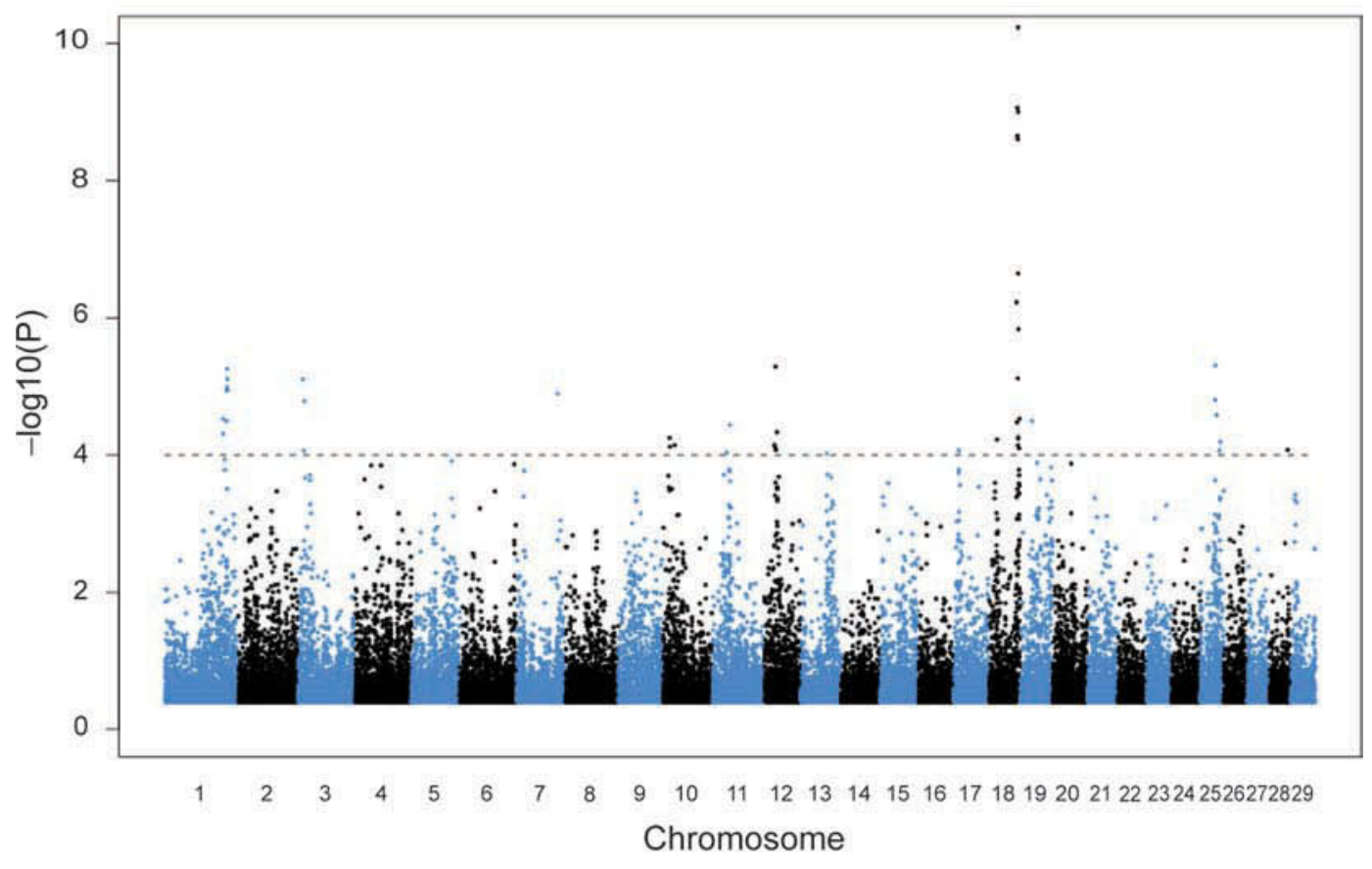

Calving Index (Cl)

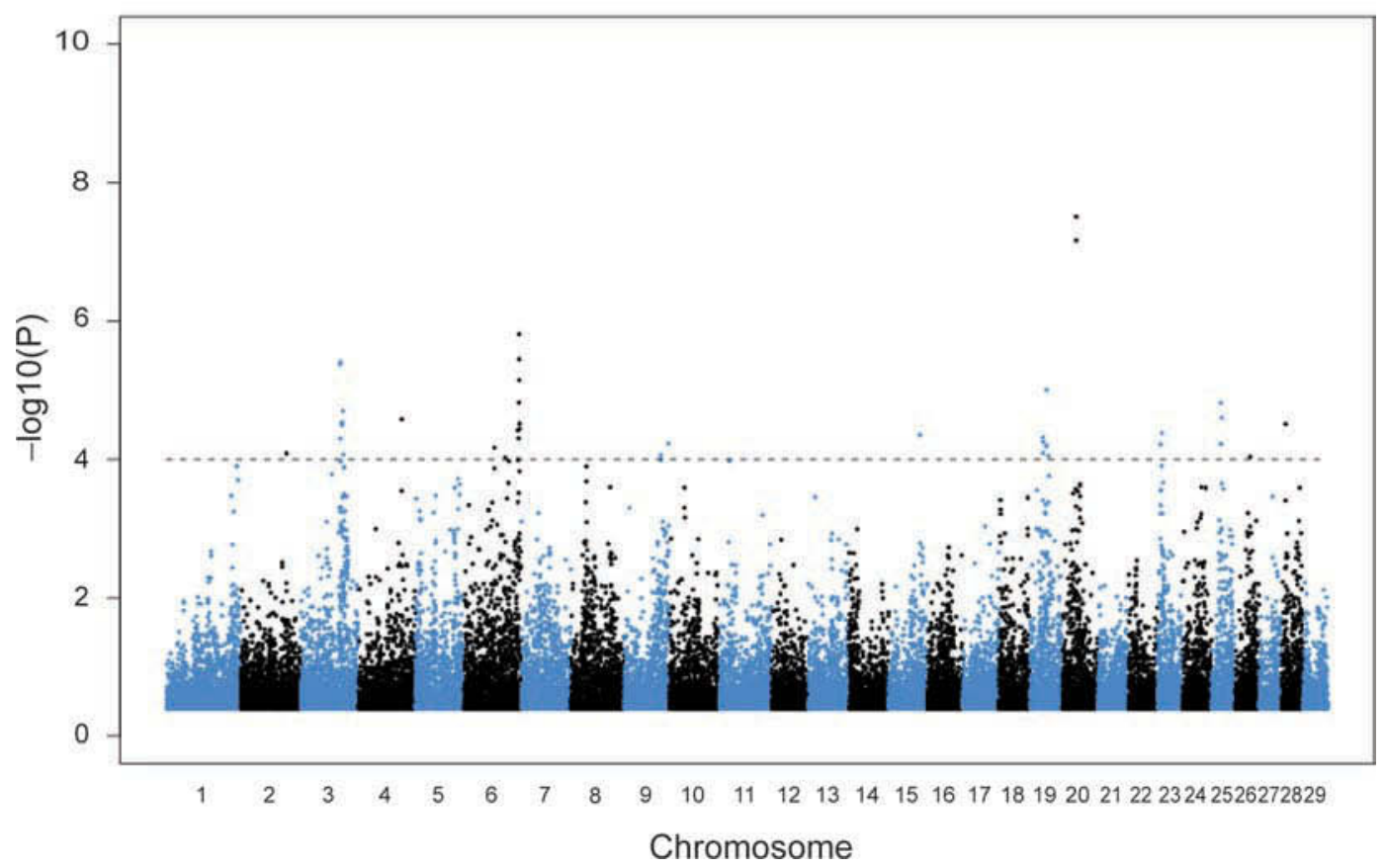

Figure 1. Genome-wide scan for birth index and calving index with $-\log _{10}$ of the $P$-value analysis for association with SNP. Chromosomes are shown in alternating shades for clarity. The dotted line shows the suggestive association $\left[-\log _{10}(P\right.$-value $\left.)=4\right]$ as considered in the present study. All panels are truncated at $-\log _{10}(P$-value $)=10$, although some markers on BTA18 exceeded this level. Color version available in the online PDF. 
pared with those obtained in earlier linkage studies in which the QTL intervals were generally very long and sometimes included whole chromosomes. This difference is primarily because association mapping utilizes population-level linkage disequilibrium and can thereby map a QTL to a short chromosomal region. Another reason for imprecise localization of QTL in the linkage studies was use of sparse microsatellite markers.

In addition, some of our present data are different from conclusions drawn in previous studies. For instance, we identified 2 QTL on BTA3 at 15.7 and 90.5 $\mathrm{Mb}$, the latter of which was located close to the QTL for DSBF (102.3 Mb) reported previously (Thomasen et al., 2008). However, we found that this QTL affects maternal calving traits, whereas Thomasen et al. (2008) reported it as having a direct effect. Complex vertebral malformation, which is an autosomal recessive inherited disorder in the Holstein breed, leads to calf mortality and abortion (Agerholm et al., 2001). The causal gene for complex vertebral malformation is located at 46.22 to $46.23 \mathrm{Mb}$ on BTA3 (Btau_4.0). The 2 QTL we detected in the present study on BTA3 were too far from the complex vertebral malformation gene location to be associated with this locus, and therefore represent novel genomic regions associated with calving traits.

Furthermore, a QTL for DCEF was previously detected on BTA4 at 59.8 $\mathrm{Mb}$ (Thomasen et al., 2008). However, we located a QTL at $46.9 \mathrm{Mb}$ on this chromosome, which was instead associated with MCEL and DSBL. In addition, a QTL affecting CE was discovered in an earlier study in the $110.2 \mathrm{Mb}$ region of BTA6 (Schnabel et al., 2005), whereas the QTL identified in the present study was located in the $118.1 \mathrm{Mb}$ region of BTA6. Previous studies have also reported a QTL affecting CS and BI via both a direct and maternal effect of calving performance at 44.2 and $26.7 \mathrm{Mb}$ on BTA6, respectively (Schrooten et al., 2000; Holmberg and Andersson-Eklund, 2006), but we observed only a chromosome-wise significant SNP affecting DCEL at $46.3 \mathrm{Mb}$ of this chromosome.

A QTL for CE was found at 88.7 to $101.3 \mathrm{Mb}$ on BTA9 in a previous study (Ashwell et al., 2005), which we also detected at $98.04 \mathrm{Mb}$. In addition, Thomasen et al. (2008) reported a QTL for MCSF at 25.7 to 33.0 $\mathrm{Mb}$. Suggestive evidence for this QTL was found in the present study, although none of the SNP association was chromosome-wise significant. Previous work has revealed a QTL on BTA10 between 64.8 to 90.1 $\mathrm{Mb}$, which is associated with CE (Kühn et al., 2003; Schnabel et al., 2005; Thomasen et al., 2008). However, on this chromosome, we observed several SNP with suggestive significance between 82.9 and $97.3 \mathrm{Mb}$ and associated with CS. Although no SNP in this region was chromosome-wise significant in the present study, evidence across several populations gave us confidence that this QTL was real.

The QTL with the highest significance in affecting direct calving traits was observed on BTA18 at 57.12 $\mathrm{Mb}$, and was reported previously (e.g., Kühn et al., 2003; Thomasen et al., 2008). Specifically, the highest significant test statistic $\left(P=7.58 \times 10^{-30}\right)$ was observed for SNP ss86324977 located at 57,125,868 bp. Cole et al. (2009) reported that the same SNP had the largest effect of all tested SNP on sire and daughter CE, rump width, stature, strength, and body depth in Holstein cattle. This SNP is in an intron of the sialic acid binding Ig-like lectin-5 gene. This gene is expressed in the human placenta and may have a role in initiation of parturition (Brinkman-Van der Linden et al., 2007). Animals homozygous for this rare SNP may express high levels of sialic acid binding Ig-like lectin-5, resulting in a leptin deficiency and leading to delayed parturition (Cole et al., 2009). The association of ss86324977 with CE, strength, stature, body depth, and rump width may be due to the increases in calf size associated with long gestation lengths (Cole et al., 2009). In fact, Cole et al. (2009) concluded that the putative QTL on BTA18 was associated with calf growth rate and showed a larger direct effect than maternal effect. We also observed a second QTL segregating on BTA18, which was located at $14.08 \mathrm{Mb}$ and affected BI, DCSF, and DCEL. Schulman et al. (2008) reported a QTL for calf mortality in Finnish Ayrshire cattle at the proximal end of this chromosome, which could be the same QTL.

In addition, we found 2 QTL on BTA25 at 17.06 and $30.58 \mathrm{Mb}$, which affect both direct and maternal calving traits. The reason for considering 2 separate QTL on BTA25 was that a 7-Mb gap without significant SNP was present between these 2 QTL intervals. However, this could be a single QTL, and the gap could be due to an error in genome assembly in Btau_4.0 (Zimin et al., 2009). On BTA26, our study detected 1 QTL at $41.95 \mathrm{Mb}$ for DCEL and DCSF, whereas Schnabel et al. (2005) previously reported a QTL for CE, with the QTL interval including almost the entire BTA26 chromosome. Furthermore, Thomasen et al. (2008) reported a DSBF QTL on this chromosome located at 41.2 to $46.0 \mathrm{Mb}$, and 1 for MSBF at 46.0 to $52.3 \mathrm{Mb}$. They also found evidence that these were 2 linked QTL, each affecting one trait, rather than 1 pleiotropic QTL influencing both of the traits.

The majority of QTL identified in the present GWAS showed an effect on more than one calving trait. With the strong general correlation among the direct calving traits, finding a high proportion of QTL affecting more than one direct calving trait was expected. For example, CE and SB have high genetic correlation (0.78 
to 0.84; Steinbock et al., 2003). The same was observed among maternal calving traits. Postmortem examination revealed that $46 \%$ of the stillbirths were due to difficult calving, and as many as $32 \%$ were born with no indication of difficult parturition, indicating that calving difficulties were not the reason for SB for these calves (Berglund et al., 2003). Therefore, some pleiotropic QTL affecting both traits are to be expected. Thomasen et al. (2008) used Bayes factors to compare hypotheses of linked QTL with hypotheses involving pleiotropic QTL and found that the evidence favored pleiotropic models over models involving linked QTL. This is in agreement with our present findings.

The number of QTL detected that affect calving traits in later parities was small compared with the number affecting calving traits in first pregnancies. This held for both direct and maternal effects. The heritability estimates for later pregnancy calving traits were much lower than those for first-calving traits (Steinbock et al., 2003). Therefore, the QTL effects in later lactation calving traits may be expected to be smaller on average when compared with the effects of QTL affecting first pregnancies, leading to a lower power for their detection. Genetic correlations in Danish Holstein cattle between first and later calving traits were estimated to range from 0.97 to 0.99 for direct calving traits, and from 0.81 to 0.89 for maternal calving traits (Aamand, 2002). Such high genetic correlations were not reflected in our results, because most of the QTL affecting firstlactation calving traits were not found to affect calving traits in later lactation. This could be due to several factors. First, the genetic factors affecting the trait may have different influences on calving performance in different lactations. Also, cows with serious calving difficulties would be culled at an early age and might not contribute to the records of later lactations. Furthermore, combining data from several lactations into one breeding value dilutes the effect of an individual QTL. Therefore, if we want to identify QTL specific to a lactation, it might be necessary to analyze data from each lactation separately.

Our GWAS confirmed several QTL identified earlier from the present population by Thomasen et al. (2008), as well as those identified in other cattle populations/ breeds. A significant improvement in QTL position estimates was found compared with estimates given earlier from linkage analysis, which will facilitate future searches for the candidate genes underlying these QTL. The results from the present study could be directly applied in the population for selecting animals possessing QTL alleles for favorable calving traits and could be used in whole-genome selection to determine a priori probabilities for the SNP in the model.

\section{ACKNOWLEDGMENTS}

This work was performed as part of the "Genomic selection-From function to efficient utilization in cattle breeding" project (grant No. 3412-08-02253) funded by the Danish Directorate for Food, Fisheries and Agri Business, Copenhagen, Denmark; VikingGenetics, Assentoft, Denmark; Nordic Genetic Evaluation, Aarhus, Denmark; and Aarhus University, Aarhus, Denmark, and the "DNA-based selection to improve disease resistance, fertility, calf survival, and production in Danish cattle" project (grant No. 3401-04-00853) funded by the Danish Directorate for Food, Fisheries and Agri Business. We thank the Nordic Cattle Genetic Evaluation for providing phenotypic data. VikingGenetics is acknowledged for providing blood and semen samples.

\section{REFERENCES}

Aamand, G. P. 2002. Avlsværdivurdering. Forbedringer indført i 2000-2001. Rep. No. 99, National Committee on Danish Cattle Husbandry. U. S. Nielsen, J. Pedersen, A. Fogh, O. M. Pedersen, M. Hansen, A. Glasius, P. Madsen, and J. Jensen, ed. National Committee on Danish Cattle Husbandry, Aarhus, Denmark.

Agerholm, J. S., C. Bendixen, O. Andersen, and J. Arnbjerg. 2001. Complex vertebral malformation in Holstein calves. J. Vet. Diagn. Invest. 13:283-289.

Ashwell, M. S., D. W. Heyen, J. I. Weller, M. Ron, T. S. Sonstegard, C. P. Van Tassell, and H. A. Lewin. 2005. Detection of quantitative trait loci influencing conformation traits and calving ease in Holstein-Friesian cattle. J. Dairy Sci. 88:4111-4119.

Berglund, B., L. Steinbock, and M. Elvander. 2003. Causes of stillbirth and time of death in Swedish Holstein calves examined post mortem. Acta Vet. Scand. 44:111-120.

Boelling, D., U. Sander Nielsen, J. Pösö, J.-A. Eriksson, and G. P. Aamand. 2007. Genetic evaluation of calving traits in Denmark, Finland, and Sweden. Interbull Bull. 37:179-184.

Brinkman-Van der Linden, E. C. M., N. Hurtado-Ziola, T. Hayakawa, L. Wiggleton, K. Benirschke, A. Varki, and N. Varki. 2007. Human-specific expression of Siglec-6 in the placenta. Glycobiology 17:922-931.

Cole, J. B., P. M. VanRaden, J. R. O'Connell, C. P. Van Tassell, T. S. Sonstegard, R. D. Schnabel, J. F. Taylor, and G. R. Wiggans. 2009. Distribution and location of genetic effects for dairy traits. J. Dairy Sci. 92:2931-2946.

Cole, J. B., G. R. Wiggans, P. M. VanRaden, and R. H. Miller. 2007. Stillbirth (co)variance components for a sire-maternal grandsire threshold model and development of a calving ability index for sire selection. J. Dairy Sci. 90:2489-2496.

Crews, D. H. Jr. 2006. Age of dam and sex of calf adjustments and genetic parameters for gestation length in Charolais cattle. J. Anim. Sci. 84:25-31.

Ducrocq, V. 2000. Calving ease evaluation on French dairy cattle bulls with a heteroskedastic threshold model. Paper G 4.2 in 51st Ann. Mtg. EAAP. EAAP, The Hague, the Netherlands.

Gutiérrez, J. P., F. Goyache, I. Fernández, I. Alvarez, and L. J. Royo. 2007. Genetic relationships among calving ease, calving interval, birth weight, and weaning weight in the Asturiana de los Valles beef cattle breed. J. Anim. Sci. 85:69-75.

Han, B., H. M. Kang, and E. Eskin. 2009. Rapid and accurate multiple testing correction and power estimation for millions of correlated markers. PLoS Genet. 5:e1000456 doi:10.1371/journal. pgen.1000456.

Hansen, M., M. S. Lund, J. Pedersen, and L. G. Christensen. 2004. Genetic parameters for stillbirth in Danish Holstein cows using a Bayesian threshold model. J. Dairy Sci. 87:706-716. 
Harbers, A., L. Segeren, and G. de Jong. 2000. Genetic parameters for stillbirth in The Netherlands. Interbull Bull. 25:117-122.

Hayes, B. J., P. J. Bowman, A. J. Chamberlain, and M. E. Goddard. 2009. Invited review: Genomic selection in dairy cattle: Progress and challenges. J. Dairy Sci. 92:433-443.

Holmberg, M., and L. Andersson-Eklund. 2006. Quantitative trait loci affecting fertility and calving traits in Swedish dairy cattle. J. Dairy Sci. 89:3664-3671.

Holmberg, M., G. Sahana, and L. Andersson-Eklund. 2007. Fine mapping of a quantitative trait locus on chromosome 9 affecting non-return rate in Swedish dairy cattle. J. Anim. Breed. Genet. 124:257-263.

Kühn, C., J. Bennewitz, N. Reinsch, N. Xu, H. Thomsen, C. Looft, G. A. Brockmann, M. Schwerin, C. Weimann, S. Hiendleder, G. Erhardt, I. Medjugorac, M. Forster, B. Brenig, F. Reinhardt, R. Reents, I. Russ, G. Averdunk, J. Blumel, and E. Kalm. 2003. Quantitative trait loci mapping of functional traits in the German Holstein cattle population. J. Dairy Sci. 86:360-368.

Liu, Y., X. Qin, X. Z. Song, H. Jiang, Y. Shen, K. J. Durbin, S. Lien, M. P. Kent, M. Sodeland, Y. Ren, L. Zhang, E. Sodergren, P. Havlak, K. C. Worley, G. M. Weinstock, and R. A. Gibbs. 2009. Bos taurus genome assembly. BMC Genomics 10:180.

Manfredi, E., V. Ducrocq, and J. L. Foulley. 1991. Genetic analysis of dystocia in dairy cattle. J. Dairy Sci. 74:1715-1723.

Pedersen, J., M. K. Sørensen, M. Toivonen, J.-A. Eriksson, and G. Pedersen Aamand. 2008. Report on Economic Basis for a Nordic Total Merit Index. Accessed Feb. 24, 2010. http://www.nordicebv.info/ NR/rdonlyres/B618C0E5-FF6F-4D31-8F86-B3CE4A140043/0/ NAV_TMI_report_lastversion_131108.pdf

Phocas, F. 2009. Genetic analysis of breeding traits in a Charolais cattle population segregating an inactive myostatin allele. J. Anim. Sci. 87:1865-1871.

Sahana, G., B. Guldbrandtsen, C. Bendixen, and M. S. Lund. 2010. Genome-wide association mapping for female fertility traits in
Danish and Swedish Holstein cattle. Anim. Genet. doi:10.1111/ j.1365-2052.2010.02064.x

Schnabel, R. D., T. S. Sonstegard, J. F. Taylor, and M. S. Ashwell. 2005. Whole genome scan to detect QTL for milk production, conformation, fertility and functional traits in two US Holstein families. Anim. Genet. 36:408-416.

Schrooten, C., H. Bovenhuis, W. Coppieters, and J. A. Van Arendonk. 2000. Whole genome scan to detect quantitative trait loci for conformation and functional traits in dairy cattle. J. Dairy Sci. 83:795-806.

Schulman, N. F. G. Sahana, M. S. Lund, S. M. Viitala, and J. H. Vilkki. 2008. Quantitative trait loci for fertility traits in Finnish Ayrshire cattle. Genet. Sel. Evol. 40:195-214.

Steinbock, L., A. Näsholm, B. Berglund, K. Johansson, and J. Philipsson. 2003. Genetic effects on stillbirth and calving difficulty in Swedish Holsteins at first and second calving. J. Dairy Sci. $86: 2228-2235$.

Wellcome Trust Case Control Consortium. 2007. Genome-wide association study of 14,000 cases of seven common diseases and 3,000 shared controls. Nature 447:661-678.

Thomasen, J. R., B. Guldbrandtsen, P. Sørensen, B. Thomsen, and M. S. Lund. 2008. Quantitative trait loci affecting calving traits in Danish Holstein cattle. J. Dairy Sci. 91:2098-2105.

Yu, J., G. Pressoir, W. H. Briggs, I. Vroh Bi, M. Yamasaki, J. F Doebley, M. D. McMullen, B. S. Gaut, D. M. Nielsen, J. B. Holland, S. Kresovich, and E. S. Buckler. 2006. A unified mixed-model method for association mapping that accounts for multiple levels of relatedness. Nat. Genet. 38:203-208.

Zimin, A. V., A. L. Delcher, L. Florea, D. R. Kelley, M. C. Schatz, D. Puiu, F. Hanrahan, G. Pertea, C. P. Van Tassell, T. S. Sonstegard, G. Marçais, M. Roberts, P. Subramanian, J. A. Yorke, and S. L. Salzberg. 2009. A whole-genome assembly of the domestic cow, Bos taurus. Genome Biol. 10:R42. 